\title{
Article \\ Study of the Effect of Leucine on Calcium Carbonate Precipitation in a Circular Economy Perspective
}

\author{
Giuseppe Mazziotti di Celso ${ }^{1}$, Marina Prisciandaro ${ }^{2, *} \mathbb{D}$, Despina Karatza ${ }^{3}$, Dino Musmarra ${ }^{3}$ (D) \\ and Amedeo Lancia 4
}

check for updates

Citation: Mazziotti di Celso, G.;

Prisciandaro, M.; Karatza, D.; Musmarra, D.; Lancia, A. Study of the Effect of Leucine on Calcium Carbonate Precipitation in a Circular Economy Perspective. Water 2022, 14, 270. https://doi.org/10.3390/ w14020270

Academic Editor: Sergi

Garcia-Segura

Received: 3 December 2021

Accepted: 13 January 2022

Published: 17 January 2022

Publisher's Note: MDPI stays neutral with regard to jurisdictional claims in published maps and institutional affiliations.

Copyright: () 2022 by the authors Licensee MDPI, Basel, Switzerland. This article is an open access article distributed under the terms and conditions of the Creative Commons Attribution (CC BY) license (https:// creativecommons.org/licenses/by/ $4.0 /)$.
1 Faculty of Bioscience, Agri-Food and Environmental Technologies, University of Teramo, 64100 Teramo, Italy; gmazziottidicelso@unite.it

2 Department of Industrial and Information Engineering and of Economics, University of L'Aquila, 67100 L'Aquila, Italy

3 Department of Engineering, University of Campania Luigi Vanvitelli, 81031 Aversa, Italy; karatza@irc.cnr.it (D.K.); dino.musmarra@unicampania.it (D.M.)

4 Department of Chemical, Materials and Production Engineering, University Federico II of Naples, 80125 Napoli, Italy; lancia@unina.it

* Correspondence: marina.prisciandaro@univaq.it

\begin{abstract}
This paper studies the crystallization of calcium carbonate in the presence of leucine-a green additive. The effect of leucine on calcium carbonate precipitation kinetic is particularly interesting since $\mathrm{CaCO}_{3}$ is a valuable product worthy to be recovered from industrial liquid wastes (e.g., desalination brines) in the circular economy approach. Experiments have been performed in a laboratory scale plant with a supersaturation range which spams from 2 to 120 and two different leucine concentration $\left(0.520 \times 10^{-3}\right.$ and $\left.1.041 \times 10^{-3} \mathrm{~mol} / \mathrm{L}\right)$. Results obtained have been compared with previous published ones, carried out without any additives. From the measurements of induction times for calcium carbonate nucleation, it was established that in solution, the leucine favors the precipitation of calcium carbonate, so it can be considered a promoter in calcium carbonate crystallization and this behavior enhances when raising its concentration in solution. Interfacial tension was determined for both leucine concentration levels, and the values obtained are in the range $51-84 \mathrm{~mJ} / \mathrm{m}^{2}$.
\end{abstract}

Keywords: calcium carbonate; green additive; leucine; desalination brines; CCU; precipitation

\section{Introduction}

Calcium carbonate crystallization plays a major role in several processes, where it can be a desired presence or an unwanted occurrence. On the one hand, calcium carbonate, together with calcium sulphate, is the main cause of scales on process equipment, like reverse osmosis membranes or multiple effect evaporators in desalination plants, thereby decreasing process efficiency [1,2]. On the other hand, precipitated calcium carbonate is a valuable product used mainly as a filler product in many industries such as paper, rubber, paint, textile, plastic, sealant, alloy, catalyst, cosmetic, pharmaceutical and the food industry [3-5]. In addition, new composites made of biopolymers and calcium carbonate are conquering market shares in recent years, due to their unique properties, applications and non-toxicity [6]. Calcium carbonate can be recovered also from calcium-rich effluents of different production processes by $\mathrm{CO}_{2}$ mineral carbonation [7]. This is particularly worthwhile as mineral carbonation of $\mathrm{CO}_{2}$ is one of the carbon capture and utilization (CCU) technologies that is thermodynamically favored and cheap; therefore, it is suitable for large-scale commercialization. This route ensures effective recycling of both gaseous $\mathrm{CO}_{2}$ and liquid industrial waste, turning $\mathrm{CO}_{2}$ into a final product of industrial interest, which is in line with a circular economy approach [8]. An industrial example is the postdistillation liquid from the Solvay Process (production of sodium carbonate, soda-ash), that 
is a Ca-rich waste [9]; if not correctly disposed of, this waste is responsible for the strong salinity of nearby groundwater with calcium chloride pollution of natural water reservoirs and soil [10]. Instead, this liquid waste can be used for $\mathrm{CaCO}_{3}$ precipitation with $\mathrm{CO}_{2}$ utilization [11]. Other examples of wastes that can be used to produce calcium carbonate via carbonation are paper sludge ash from paper manufacturing and oil shale ash [10] and desalination brines. As pointed out by the recent review by Ogunbiyi and coworkers [12], the recovery of valuable minerals among which $\mathrm{CaCO}_{3}$ from desalination brines is a key feature in brine management that is gaining increasing interest in scientific literature. This because $\mathrm{CaCO}_{3}$ recovery processes from brines are methods of limiting $\mathrm{CO}_{2}$ emissions or removing $\mathrm{CO}_{2}$ from desalination plants [13].

In those cases, when carbonate is the desired product of the process, it may be crucial to have the possibility of producing $\mathrm{CaCO}_{3}$ with the desired characteristics, such as purity, water content, particle size and shape and polymorphic form [6].

In order to obtain $\mathrm{CaCO}_{3}$ crystals with the preferred features and to promote crystallization, the addition of additives in a supersaturated solution is a common technique, usually employed to modify and influence nucleation and crystal growth mechanisms. The selection of the proper additive depends upon the water chemistry and the system design [14]. Several compounds have been tested for their ability to favor calcium carbonate precipitation, such as EDTA and $\mathrm{ZnCl}_{2}$ [15], polyacrylic acid (PAA) [16-18], Sodium dodecyl sulfate (SDS) [19] and other substances. The article by Jimoh and coworkers [4] gives an exhaustive state of the art of the different additives on precipitated calcium carbonate (PCC) syntheses, where PCC is that produced in a precipitation reaction by reacting aqueous calcium hydroxide, $\mathrm{Ca}(\mathrm{OH})_{2}$ with carbon dioxide $\left(\mathrm{CO}_{2}\right)$ ("carbonation"). Nowadays, more and more research is aimed at finding alternatives, the so called "green calcium carbonate scaling inhibitors" especially for $\mathrm{CaCO}_{3}$ production in food and drug industrial applications. An additive may be defined as a green if it is non-toxic, non-bioaccumulating and biodegradable. For example, in the last years, lots of ecological additives have been studied, like plant extracts. They represent an interesting solution because they are green and environment-friendly, and they can be extracted easily. A literature survey has shown that leucine had a profound effect on the crystallization behavior and especially on the morphology of $\mathrm{CaCO}_{3}$ crystals [20]. Even if there is a vast literature that studies the influence of various amino acids on carbonate precipitation [21-24], however, the effect of such a molecule on both the nature of nucleation (homogeneous or heterogeneous mechanism) together with growth kinetics of $\mathrm{CaCO}_{3}$ has been poorly studied so far; the only paper found on the effect of leucine on carbonate growth kinetic is the study by Malkaj and coworkers [25], who found that in heterogeneous nucleation conditions, leucine had no effect on the growth mechanism. Again, only an effect on the morphology and the particle size of the $\mathrm{CaCO}_{3}$ was observed. On the contrary, leucine had proved to have a strong effect on the crystal growth rates of hydroxyapatite (HAP), that decreased markedly due to adsorption of leucine and subsequent blocking of the active growth sites onto the surface of the HAP crystals [26]. The effect of this natural amino acid on nucleation and crystal growth on calcium carbonate would be extremely interesting also due to its characteristics that meet the requirements for applications in the food and beverage industries $[27,28]$.

The analysis of the literature has thus indicated the need of deepening the effect of the natural additive leucine on nucleation and crystal growth on calcium carbonate precipitation via the estimation of thermodynamic parameters, such as the interfacial tension. This parameter, estimated through the measurement of induction times for the nucleation, would allow to verify if the addition of leucine in solution could accelerate the precipitation of calcium carbonate so as to allow a correct/suitable use of the additive in its industrial applications.

The generally accepted classical laws of crystallization affirm that the formation of calcium carbonate crystals occurs through the formation of nuclei (nucleation) in a supersaturated solution, followed, or accompanied by crystal growth (growth). An additive in a supersaturated solution may affect one or both these mechanisms. According to 
Mersmann [29], the exact mode of operation of these substances at the molecular level is still, by and large, obscure. Any theory trying to explain the role played by these molecules must consider the structural parameters of the growing crystals, their morphologies and the stereochemistry of the impurities. However, as shown in detail by other studies by the same research group [30], the effect of different additives on nucleation kinetics can be carried out by evaluating the induction period $t_{\text {ind }}$, defined as the time that elapses between the onset of supersaturation and the first changes in the system's physical properties due to the formation of a solid phase [31]. Therefore, with experiments in the presence and in the absence of the additive, it is possible to define the promoting effect of the selected additive if it proves itself able to decrease the induction time for nucleation.

In this paper, the effect of leucine addition on calcium carbonate crystallization from solution is studied through the measure of induction time for nucleation, with the experimental technique set up by this research group [32]. As shown by Mullin [33] and Söhnel and Garside [34], $t_{\text {ind }}$ dependence on supersaturation allows the determination of the interfacial tension between crystals and the surrounding solution. Therefore, the value of interfacial tension of calcium carbonate crystals is estimated, in the presence and in the absence of leucine.

\section{Materials and Methods}

The experimental apparatus is a laboratory scale plant, provided with a jacketed stirred reactor and an optical device. It is sketched in Figure 1 and a detailed description of the apparatus and the related optical technique used for the measurement of the induction time for nucleation is available elsewhere [32].

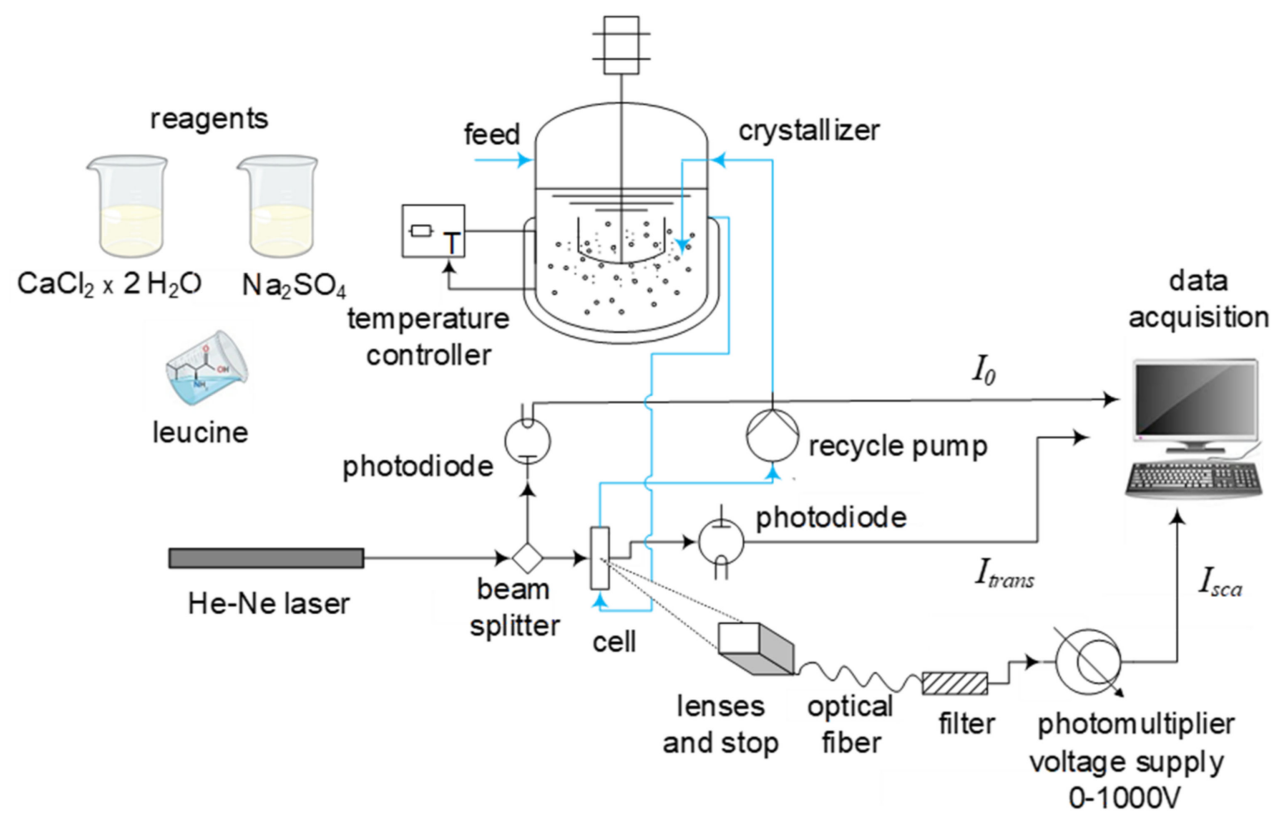

Figure 1. Experimental apparatus.

To prepare the calcium carbonate supersaturated solution to fill in the stirring reactor, three reagents have been mixed together with bi-distillate water: calcium chloride dihydrate $\left(\mathrm{CaCl}_{2} \cdot 2 \mathrm{H}_{2} \mathrm{O}\right)$, sodium hydrogen carbonate $\left(\mathrm{NaHCO}_{3}\right)$ (both from Applichem, Darmstadt, Germany) and leucine (L-leucine-Merck LifeScience, Darmstadt, Germany). EDTA titrimetric method was used to measure $\mathrm{Ca}^{2+}$ ions concentration in reagent solution.

Before filling in the reactor, the solution was micro-filtered, to separate foreign substances. All experimental runs have been performed at room temperature $\left(T=25^{\circ} \mathrm{C}\right)$. Different values of $\mathrm{CaCl}_{2} \cdot 2 \mathrm{H}_{2} \mathrm{O}$ and $\mathrm{NaHCO}_{3}$ have been used, ranging from 2 to $60 \mathrm{~mol} / \mathrm{m}^{3}$, while two concentrations of leucine $0.520 \times 10^{-3}$ and $1.041 \times 10^{-3} \mathrm{~mol} / \mathrm{L}$ have been selected. 
Experimental runs have been carried out at room temperature $\left(T=25^{\circ} \mathrm{C}\right)$, with supersaturation ratio values ranging from 2 to 120 .

Considering the liquid-solid equilibrium between the species in solution $\left(\mathrm{Ca}^{2+}\right.$ and $\mathrm{CO}_{3}^{2-}$ ions) and the precipitate calcium carbonate:

$$
\mathrm{Ca}^{2+}+\mathrm{CO}_{3}^{2-}=\mathrm{CaCO}_{3}
$$

the supersaturation ratio is computed by the following equation:

$$
S=\frac{a_{C a^{2+}} a_{C O}^{2-}}{K_{p s}}
$$

where

$a_{\mathrm{Ca}^{2+}}=$ calcium ion activity

$a_{\mathrm{CO}_{3}^{2-}}=$ carbonate ion activity

$K_{p s}=$ solubility product of calcium carbonate.

The activity $(a)$ of each ion may be calculated by multiplying the molality $(m)$ by the activity coefficient $(\gamma)$, respectively, which can be finally achieved from modified DeybeHückel equation [35] while $K_{p s}$ depends on the temperature and may be calculated by the following equation, valid for calcite [36]:

$$
p K_{p s}=0.001183 T+8.03
$$

All concentrations have been calculated accounting for all the equilibria that settle in the aqueous solution, as described in the Appendix A.

Samples of the precipitated solid were analyzed with XRD (Malvern PANalytical, Malvern, UK), and the analysis confirmed that it was mainly made of calcite.

\section{Results and Discussion}

To study the effect of leucine addition on calcium carbonate nucleation, two experimental series for the induction time measurement have been performed at different leucine concentrations, keeping the temperature constant at $T=25^{\circ} \mathrm{C}$ and varying the supersaturation ratio $S$. The first experimental series has been carried out at a leucine concentration $\left(c_{\text {LEU }}\right)$ equal to $0.520 \times 10^{-3} \mathrm{M}$, the second one at $c_{L E U}=1.041 \times 10^{-3} \mathrm{M}$. The experiments are reported in the following Figure 2, where induction times are plotted as a function of supersaturation ratios for two leucine levels. As can be observed, for each curve at a fixed leucine concentration, the induction times decrease with increasing of the supersaturation ratio. This is expected, since a higher ion concentration in solution results in a faster solid phase formation [33]. With increasing leucine concentration, passing from $0.520 \times 10^{-3} \mathrm{M}$ (rhombuses) to $1.041 \times 10^{-3} \mathrm{M}$ (circles), the induction times decrease and the curve moves downwards. Leucine seems to behave as a promoter for $\mathrm{CaCO}_{3}$ crystallization. This behavior is likely due to the fact that when leucine is added in solution, the distance between the equilibrium and the metastable curves decreases, reducing the so-called metastable zone. This is an advantage if the target is to recover calcium carbonate with specific characteristics in terms of particle size, purity, shape and polymorphic form. The promotion for $\mathrm{CaCO}_{3}$ crystallization can be enhanced, as shown by the curves reported in Figure 2, if higher leucine concentration is added to the solution, which leads to lower induction times at the same supersaturation ratio. 


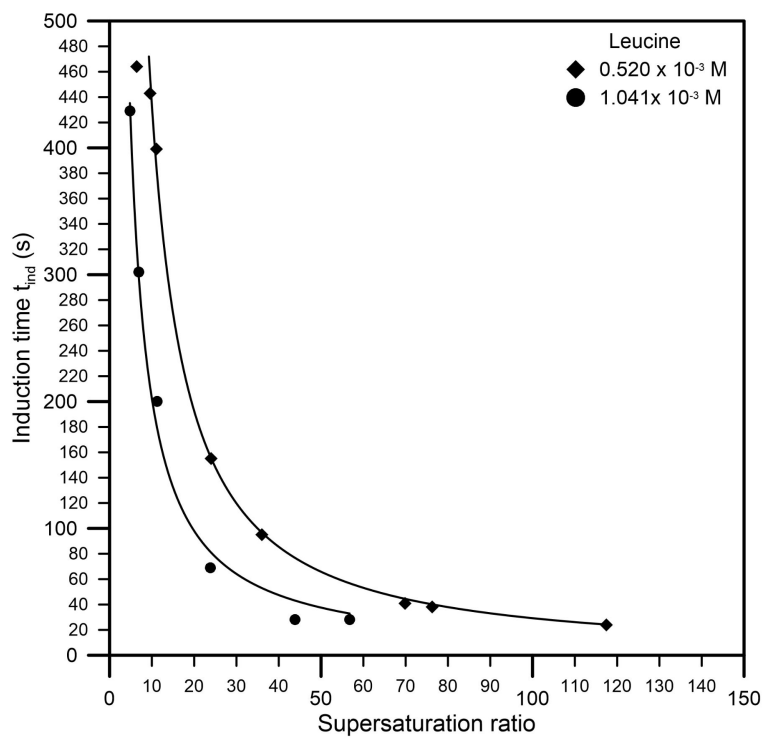

Figure 2. Induction time for $\mathrm{CaCO}_{3}$ nucleation as a function of supersaturation ratio at different leucine concentrations.

To strengthen this experimental observation, experimental results have been compared with those obtained by the same research group in the absence of any additive $[37,38]$. The comparison, at fixed additive concentration (leucine) of $0.520 \times 10^{-3} \mathrm{M}$, is shown in Figure 3 . The figure shows the $t_{\text {ind }}$ values measured in presence of leucine (rhombuses), at the same concentration in solution, are lower than the induction times values obtained in the absence of any additives (triangles). This confirms the capacity of leucine to act as a promoter for calcium carbonate nucleation.

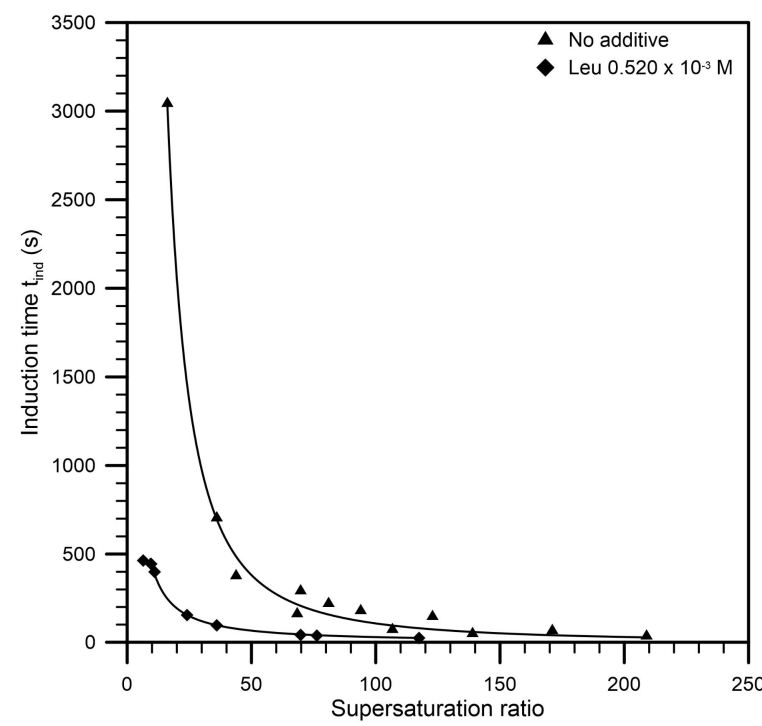

Figure 3. Induction time for $\mathrm{CaCO}_{3}$ nucleation as a function of supersaturation ratio with leucine and without any additive.

Experimental results shown in Figures 2 and 3 have been fitted using the following equation:

$$
t_{\text {ind }}=\frac{k}{S^{r}}
$$

where the induction time $\left(t_{\text {ind }}\right)$ and the supersaturation ratio $(S)$ are linked together by means of two empirical constants $(k, r)$, that have been evaluated and reported in Table 1 
for both concentrations of leucine investigated and in the case of no additive in solution computed in a previous paper [39].

Table 1. Empirical constants for all experimental runs.

\begin{tabular}{cccc}
\hline Leucine (M) & $\boldsymbol{k}$ & $\boldsymbol{r}$ & $\mathbf{R}^{\mathbf{2}}$ \\
\hline 0 & $1.08 \times 10^{6}$ & 2.11 & 0.991 \\
$0.520 \times 10^{-3}$ & $6.43 \times 10^{3}$ & 1.17 & 0.998 \\
$1.041 \times 10^{-3}$ & $2.25 \times 10^{3}$ & 1.05 & 0.993 \\
\hline
\end{tabular}

Subsequently, induction time measurements as a function of supersaturation ratio have been used to estimate the interfacial tension between $\mathrm{CaCO}_{3}$ crystals and surrounding solution. The linearization of experimental results has been computed, according to the following equation derived from the classical crystallization theory [33]:

$$
\log \left(t_{\text {ind }}\right)=C_{N}+\frac{D_{N}}{T^{3}(\log S)^{2}}
$$

where

$C_{N}=$ empirical constant

$T=$ absolute temperature, $K$

$S=$ supersaturation ratio

$$
D_{N}=\frac{\beta \times \gamma_{s l}^{3} \times V_{m}^{2} \times N_{A} \times f(\phi)}{(2.3 R)^{3} v^{2}}
$$

$\beta=$ shape factor.

$\gamma_{s l}=$ interfacial tension, $\mathrm{J} / \mathrm{m}^{2}$.

$V_{m}=$ molar volume, $\mathrm{m}^{3} / \mathrm{mol}$.

$N_{A}=$ Avogadro number, $\mathrm{L} / \mathrm{mol}$.

$f(\phi)=$ correction factor $(<1$ heterog. nucl. $=1$ homog. nucl. $)$.

$R=$ gas constant, $\mathrm{J} / \mathrm{mol} \mathrm{K}$.

$v=$ number of ions.

As reported in the literature for calcium carbonate crystallization [33], it is possible to say that nucleation is the key phase to control the induction time value $\left(t_{n} \gg t_{g}\right.$, $t_{n}=$ nucleation time, $t_{g}=$ growth time). Therefore, experimental results can be linearized in the two cases investigated using Equation (5), with different leucine concentrations. The results of linearization have been reported in Figure 4 for leucine concentration $0.520 \times 10^{-3} \mathrm{M}$.

It is well visible that $t_{\text {ind }}$ values belong to two different groups: the points obtained at higher supersaturation ratio values (left side of the plot) are representative of the homogeneous nucleation mechanism, and thus can be used for interfacial tension $\left(\gamma_{s l}\right)$ determination; the other points (at lower S, right side of the plot), belong to the heterogeneous nucleation region. From the slope of solely homogeneous data, the value of $\gamma_{s l}=84.05 \mathrm{~mJ} / \mathrm{m}^{2}$ is estimated.

When the concentration of leucine is low $\left(0.520 \times 10^{-3} \mathrm{M}\right)$ the transition zone is still well defined, both with the homogeneous and heterogeneous nucleation shown. This behavior was somehow expected. The heterogeneous nucleation is typical of low supersaturation values: when the additive is a promoter, like leucine, in the region of low supersaturation values, induction time can be easily investigated by the acquisition system, as the formation of the first crystalline nuclei to appear is still very rapid. 


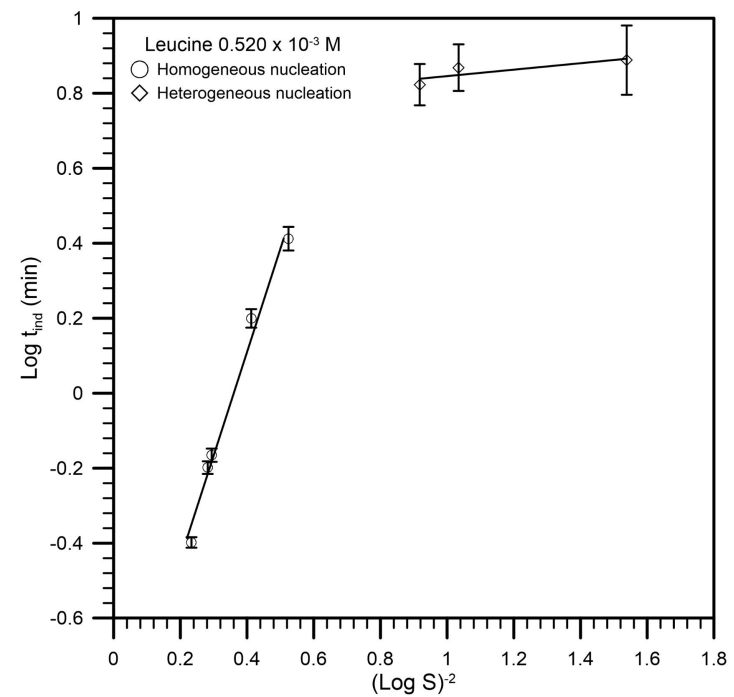

Figure 4. Induction period as a function of the inverse of supersaturation ratio: homogeneous and heterogeneous nucleation with leucine $\left(c_{L E U}=0.520 \times 10^{-3} \mathrm{M}\right)$.

In Figure 5, the same information as Figure 4 is reported with the increased leucine concentration $\left(1.041 \times 10^{-3} \mathrm{M}\right)$. Also in this case, the transition zone can be evaluated, and the mechanism involving homogeneous nucleation was exclusively used for the estimation of interfacial tension data [39]. As can be noted, the transition region between homogeneous and heterogeneous nucleation for higher leucine concentration $\left(1.041 \times 10^{-3} \mathrm{M}\right)$, shift towards right (at higher $1 /(\log S)^{-2}$ levels); that is, the transition occurs at lower supersaturation levels. This behavior can be explained as follows: at higher leucine concentration, also at low supersaturation values, induction times are very short, as confirmed by the curve reported in Figure 2. This implies a rapid nucleation of a large number of crystals, which in a few seconds, makes the whole $\mathrm{CaCO}_{3}$ to precipitate, as a consequence of the extremely high rate of crystal precipitation triggered by the unavoidably foreign substances in solution (heterogeneous conditions).

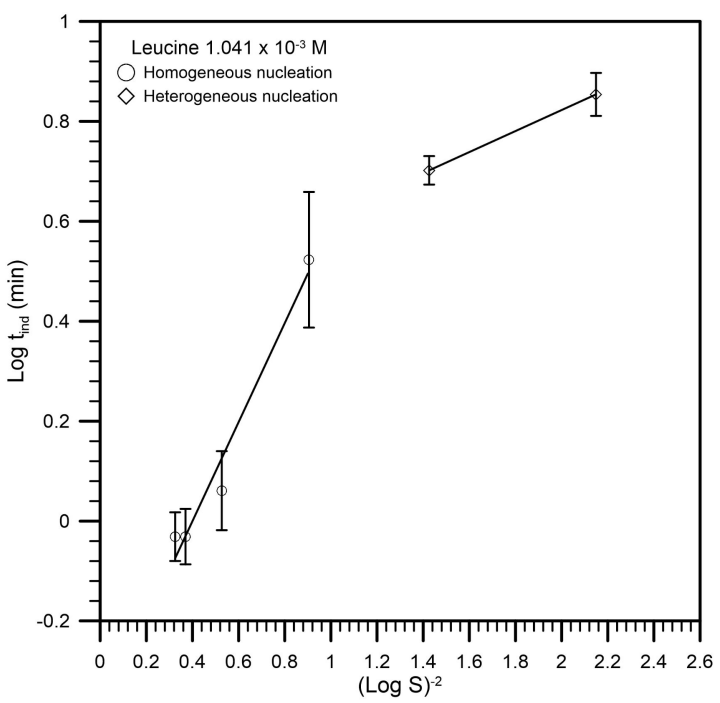

Figure 5. Induction period as a function of the inverse of supersaturation ratio: homogeneous nucleation with leucine $\left(c_{L E U}=1.041 \times 10^{-3} \mathrm{M}\right)$.

As can be seen, with increasing leucine concentrations, interfacial tension decreases, which confirms that the formation of $\mathrm{CaCO}_{3}$ nuclei is faster in the presence of a higher 
leucine concentration. The table also shows that interfacial tension $\gamma_{s l}$ in the absence of any additive is higher than the case in which a promoter is added in solution.

Finally, for both leucine concentrations interfacial tension has been estimated and the computed values have been reported in Table 2.

Table 2. Interfacial tension as a function of additive concentration.

\begin{tabular}{cc}
\hline $\begin{array}{c}\text { Additive } \\
\text { Concentration (M) }\end{array}$ & $\begin{array}{c}\text { Interfacial Tension } \\
\gamma_{s l}\left(\mathbf{m J} / \mathbf{m}^{2}\right)\end{array}$ \\
\hline 0 & 109.3 \\
$0.520 \times 10^{-3}$ & 84.05 \\
$1.041 \times 10^{-3}$ & 68.90 \\
\hline
\end{tabular}

\section{Conclusions}

In this paper, the effect of leucine on the induction time and the nucleation mechanisms of calcium carbonate crystallization has been studied. Two different concentrations of leucine in solution have been investigated, and the experimental runs, compared with previously published results with no additive, have shown that leucine is a promoter for $\mathrm{CaCO}_{3}$ precipitation, and this behavior increases, if its concentration grows from $0.520 \times 10^{-3} \mathrm{M}$ to $1.041 \times 10^{-3} \mathrm{M}$. In both cases, the nucleation mechanisms were investigated: a twofold kind of nucleation (homogeneous/heterogeneous) was detected for a leucine concentration equal to $0.520 \times 10^{-3} \mathrm{M}$, while homogeneous nucleation only was individuated for a leucine concentration equal to $1.041 \times 10^{-3} \mathrm{M}$. The values of interfacial tension were estimated, showing that they increase along with the leucine concentration, confirming its nature of promoting additive. The obtained results are particularly relevant when calcium carbonate is precipitated from the post-distillation waste solution generated, as for example, in the Solvay process, or when calcium carbonate, being a sparingly soluble salt, is to be precipitated to reduce the risk of $\mathrm{RO}$ membrane scaling and damage in $\mathrm{RO}$ desalination plants, or at least recovered from desalination brines. In each of the abovementioned applications, $\mathrm{CaCO}_{3}$ precipitation in the presence of leucine is an interesting approach to waste management in the view of a circular economy. Moreover, the leucine addiction may expedite the $\mathrm{CaCO}_{3}$ formation, allowing its recovery also when calcium carbonate is to be used in processes where no pollutant additive may be allowable, as in the field of pharmaceutical and food industries.

Author Contributions: Resources, A.L.; conceptualization M.P. and D.M.; investigation D.K.; data curation G.M.d.C. and D.M.; software G.M.d.C.; supervision A.L. and D.K.; writing-review and editing M.P. All authors have read and agreed to the published version of the manuscript.

Funding: This research received no external funding.

Institutional Review Board Statement: Not applicable.

Informed Consent Statement: Not applicable.

Data Availability Statement: Not applicable.

Conflicts of Interest: The authors declare no conflict of interest.

\section{Appendix A}

In this paper, equilibria in solutions have been calculated according to the following equations:

$$
\begin{gathered}
\mathrm{H}_{2} \mathrm{CO}_{3} \stackrel{K_{1}}{\leftrightarrow} \mathrm{HCO}_{3}^{-}+\mathrm{H}^{+} \\
\mathrm{HCO}_{3}^{-} \stackrel{K_{2}}{\leftrightarrow} \mathrm{CO}_{3}^{2-}+\mathrm{H}^{+} \\
\left(\mathrm{HCO}_{3}^{-}\right)_{\mathrm{Na}}=\mathrm{H}_{2} \mathrm{CO}_{3}+\mathrm{HCO}_{3}^{-}+\mathrm{CO}_{3}^{2-}
\end{gathered}
$$




$$
\begin{gathered}
\mathrm{H}_{2} \mathrm{O} \stackrel{K_{W}}{\leftrightarrow} \mathrm{H}^{+}+\mathrm{OH}^{-} \\
\mathrm{C}_{6} \mathrm{H}_{13} \mathrm{NO}_{2} \stackrel{K_{L 1}}{\leftrightarrow} \mathrm{C}_{6} \mathrm{H}_{12} \mathrm{NO}_{2}^{-}+\mathrm{H}^{+} \\
\mathrm{C}_{6} \mathrm{H}_{12} \mathrm{NO}_{2}^{-} \stackrel{K_{L 2}}{\leftrightarrow} \mathrm{C}_{6} \mathrm{H}_{11} \mathrm{NO}_{2}^{2-}+\mathrm{H}^{+} \\
\mathrm{C}_{6} \mathrm{H}_{13} \mathrm{NO}_{2}=\mathrm{C}_{6} \mathrm{H}_{13} \mathrm{NO}_{2}+\mathrm{C}_{6} \mathrm{H}_{12} \mathrm{NO}_{2}^{-}+\mathrm{C}_{6} \mathrm{H}_{11} \mathrm{NO}_{2}^{2-} \\
\mathrm{Na}^{+}+2 \mathrm{Ca}^{2+}+\mathrm{H}^{+}-\mathrm{OH}^{-}-\mathrm{HCO}_{3}^{-}-2 \mathrm{CO}_{3}^{2-}-\mathrm{Cl}^{-}-\mathrm{C}_{6} \mathrm{H}_{12} \mathrm{NO}_{2}^{-}-\mathrm{C}_{6} \mathrm{H}_{11} \mathrm{NO}_{2}^{2-}=0
\end{gathered}
$$

In Table A1, the dissociation constants computed at room temperature have been reported, while Table A2 shows the molarity of salts in solution, molarity of $\mathrm{Ca}^{2+}, \mathrm{CO}_{3}^{2-}$, their activity coefficient and supersaturation ratio $(S)$ for some experimental runs, in the case of $0.520 \times 10^{-3} \mathrm{M}$ leucine added in solution.

Table A1. Dissociation constants.

\begin{tabular}{ccccc}
\hline$K_{1}$ & $K_{2}$ & $K_{W}$ & $K_{L 1}$ & $K_{L 2}$ \\
\hline $4.45 \times 10^{-7}$ & $4.69 \times 10^{-11}$ & $1 \times 10^{-14}$ & $7.41 \times 10^{-4}$ & $1.75 \times 10^{-5}$ \\
\hline
\end{tabular}

Table A2. Activities and supersaturation in solution.

\begin{tabular}{ccccccc}
\hline Salts $\mathbf{( M )}$ & $\mathbf{C a}^{2+} \mathbf{( M )}$ & $\mathbf{C O}^{2-} \mathbf{( M )}$ & $\gamma_{\mathbf{C a}^{2+}}$ & $\gamma_{\mathrm{CO}_{3}^{2-}}$ & $\boldsymbol{K}_{p s}$ & $S$ \\
\hline 0.01150 & 0.01150 & $2.29 \times 10^{-5}$ & 0.4369 & 0.4369 & $5.22 \times 10^{-9}$ & 9.62 \\
0.01598 & 0.01598 & $4.53 \times 10^{-5}$ & 0.3886 & 0.3886 & $4.54 \times 10^{-9}$ & 24.04 \\
0.02870 & 0.02870 & $1.29 \times 10^{-4}$ & 0.3063 & 0.3063 & $4.57 \times 10^{-9}$ & 76.26 \\
\hline
\end{tabular}

\section{Where}

$K_{1}, K_{2}$ are the dissociation constants of carbonic acid

$K_{W}$, is the dissociation constant of water

$K_{L 1}, K_{L 2}$ are the dissociation constants of leucine

$K_{p s}$ is the solubility product, evaluated using Equation (3)

$\gamma_{\mathrm{Ca}^{2+}}, \gamma_{\mathrm{CO}_{3}^{2-}}$ are the activity coefficients of $\mathrm{Ca}^{2+}$ and $\mathrm{CO}_{3}^{2-}$.

Supersaturation values shown in Table A2 have been computed solving Equation (2), for particular experimental runs, in the case of different concentrations of leucine $(0.520 \times$ $10^{-3} \mathrm{M}$ and $1.041 \times 10^{-3} \mathrm{M}$ ) added in solution. Activity coefficients as a function of ionic strength for both calcium and carbonate have been computed using the extended DebyeHückel model [34]:

$$
\log \gamma_{J}=-A z_{J}^{2}\left(\frac{\sqrt{F I}}{1+a \sqrt{F I}}-b F I\right)
$$

$z_{J}=$ the charge of $J$ species,

$F I=$ ionic strength $\left(\mathrm{mol} / \mathrm{dm}^{3}\right)$ of the solution

$a=1$, constant $\left(\mathrm{dm}^{3 / 2} / \mathrm{mol}^{1 / 2}\right)$

$b=0.01$, constant $\left(\mathrm{dm}^{3} / \mathrm{mol}\right)$

$A=$ constant $\left(\mathrm{dm}^{3 / 2} / \mathrm{mol}^{1 / 2}\right)$ which is a function of the temperature $A=1.82 \times 10^{6}(\varepsilon T)^{-3 / 2}$

$T=$ absolute temperature $(K)$

$\varepsilon=$ dielectric constant of water

By means of the following equation, the ionic strength can be calculated:

$$
F I=\frac{1}{2} \sum_{j=1}^{n} c_{J} z_{J}^{2}
$$

$c_{J}=$ concentration of $J$ species $\left(\mathrm{mol} / \mathrm{dm}^{3}\right)$. 


\section{References}

1. Zhao, J.; Wang, M.; Lababidi, H.M.; Al-Adwani, H.; Gleason, K.K. A review of heterogeneous nucleation of calcium carbonate and control strategies for scale formation in multi-stage flash (MSF) desalination plants. Desalination 2018, 442, 75-88. [CrossRef]

2. Hoek, E.M.; Jassby, D.; Kaner, R.B.; Wu, J.; Wang, J.; Liu, Y.; Rao, U. Sustainable Desalination and Water Reuse; Morgan \& Claypool Publishers: Williston, VT, USA, 2021.

3. Erdogan, N.; Eken, H.A. Precipitated calcium carbonate production, synthesis and properties. Phys. Probl. Min. Process. 2017, 53, $57-68$.

4. Jimoh, O.A.; Ariffin, K.S.; Bin Hussin, H.; Temitope, A.E. Synthesis of precipitated calcium carbonate: A review. Carbonates Evaporites 2018, 33, 331-346. [CrossRef]

5. Xu, Y.; Ye, J.; Zhou, D.; Su, L. Research progress on applications of calcium derived from marine organisms. Sci. Rep. 2020, 10, 18425. [CrossRef]

6. Declet, A.; Reyes, E.; Suarez, O.M. Calcium carbonate precipitation: A review of the carbonate crystallization process and applications in bioinspired composites. Rev. Adv. Mater. Sci. 2016, 44, 87-107.

7. Yadav, V.K.; Yadav, K.K.; Cabral-Pinto, M.M.S.; Choudhary, N.; Gnanamoorthy, G.; Tirth, V.; Prasad, S.; Khan, A.H.; Islam, S.; Khan, N.A. The Processing of Calcium Rich Agricultural and Industrial Waste for Recovery of Calcium Carbonate and Calcium Oxide and Their Application for Environmental Cleanup: A Review. Appl. Sci. 2021, 11, 4212. [CrossRef]

8. Czaplicka, N.; Konopacka-Łyskawa, D. Utilization of Gaseous Carbon Dioxide and Industrial Ca-Rich Waste for Calcium Carbonate Precipitation: A Review. Energies 2020, 13, 6239. [CrossRef]

9. Czaplicka, N.; Konopacka-Łyskawa, D.; Lewandowska, P.; Łapiński, M.; Bray, R. Influence of selected $\mathrm{CO}_{2}$ absorption promoters on the characteristics of calcium carbonate particles produced by carbonation of the post-distillation liquid from the Solvay process. Powder Technol. 2021, 391, 432-441. [CrossRef]

10. Chang, R.; Kim, S.; Lee, S.; Choi, S.; Kim, M.; Park, Y. Calcium Carbonate Precipitation for $\mathrm{CO}_{2}$ Storage and Utilization: A Review of the Carbonate Crystallization and Polymorphism. Front. Energy Res. 2017, 10, 5-17. [CrossRef]

11. Bang, J.-H.; Yoo, Y.; Lee, S.-W.; Song, K.; Chae, S. CO 2 Mineralization Using Brine Discharged from a Seawater Desalination Plant. Minerals 2017, 7, 207. [CrossRef]

12. Ogunbiyi, O.; Saththasivam, J.; Al-Masri, D.; Manawi, Y.; Lawler, J.; Zhang, X.; Liu, Z. Sustainable brine management from the perspectives of water, energy and mineral recovery: A comprehensive review. Desalination 2021, 513, 115055. [CrossRef]

13. Bang, J.H.; Chae, S.C.; Lee, S.W.; Kim, J.W.; Song, K.; Kim, J.; Kim, W. Sequential carbonate mineralization of desalination brine for $\mathrm{CO}_{2}$ emission reduction. J. $\mathrm{CO}_{2}$ Util. 2019, 33, 427-433. [CrossRef]

14. Amjad, Z. Scale inhibition in desalination applications: An overview. In Corrosion 96; NACE-96-230; OnePetro: Richardson, TX, USA, 1996.

15. Xiang, L.; Xiang, Y.; Wang, Z.G.; Jin, Y. Influence of chemical additives on the formation of super-fine calcium carbonate. Powder Technol. 2002, 126, 129-133. [CrossRef]

16. Mantilaka, M.M.; Karunaratne, D.G.; Rajapakse, R.M.; Pitawala, H.M. Precipitated calcium carbonate/poly(methyl methacrylate) nanocomposite using dolomite. Synth. Charact. Prop. 2013, 235, 628-632.

17. Cai, G.-B.; Zhao, G.-X.; Wang, X.-K.; Yu, S.-H. Synthesis of polyacrylic acid stabilized amorphous calcium carbonate nanoparticles and their application for removal of toxic heavy metal ions in water. J. Phys. Chem. C 2010, 114, 12948-12954. [CrossRef]

18. Hwang, D.J.; Yu, Y.H.; Baek, C.S.; Lee, G.M.; Cho, K.H.; Ahn, J.W.; Han, C.; Lee, J.D. Preparation of high purity PCC from mediumand low-grade limestones using the strongly acidic cation exchange resin. J. Ind. Eng. Chem. 2015, 30, 309-321. [CrossRef]

19. Szczes, A.; Chibowski, E.; Hołysz, L. Influence of ionic surfactants on the properties of freshly precipitated calcium carbonate. Colloids Surf A 2007, 297, 14-18. [CrossRef]

20. Euliss, L.E.; Bartl, M.H.; Stucky, G.D. Control of calcium carbonate crystallization utilizing amphiphilic block copolypeptides. J. Cryst. Growth 2006, 286, 424-430. [CrossRef]

21. Picker, A.; Kellermeier, M.; Seto, J.; Gebauer, D.; Cölfen, H. The multiple effect of amino acids on the early stages of calcium carbonate crystallization. Z. Krist. Cryst. Miner. 2012, 227, 744-757. [CrossRef]

22. Thompson, S.P.; Parker, J.E.; Street, S.R.; Tang, C.C. Morphological templating of metastable calcium carbonates by the amino acid leucine. J. Phys. Conf. Ser. 2010, 286, 012030. [CrossRef]

23. Borukhin, S.; Bloch, L.; Radlauer, T.; Hill, A.H.; Fitch, A.N.; Pokroy, B. Screening the incorporation of amino acids an inorganic crystalline host: The case of calcite. Adv. Funct. Mater. 2012, 22, 4216-4224. [CrossRef]

24. Christoph, B.; Seto, J. Single amino acids as additives modulating $\mathrm{CaCO}_{3}$ mineralization. Adv. Top. Biominer. 2012, 17, 33-48.

25. Malkaj, P.; Kanakis, I.; Dalas, E. The effect of leucine on the crystal growth of calcium carbonate. J. Cryst. Growth 2004, 266, 533-538. [CrossRef]

26. Dalas, E.; Malkaj, P.; Vasileiou, Z.; Kanellopoulou, D.G. The effect of Leucine on the crystal growth of calcium phosphate. J. Mater Sci. Mater. Med. 2008, 19, 277-282. [CrossRef]

27. Chaussemier, M.; Pourmohtasham, E.; Gelus, D.; Pécoul, N.; Perrot, H.; Lédion, J.; Cheap-Charpentier, H.; Horner, H.O. State of art of natural inhibitors of calcium carbonate scaling. A review article. Desalination 2015, 356, 47-55. [CrossRef]

28. Hasson, D.; Shemer, H.; Sher, A. State of the art of friendly "green" scale control inhibitors: A review article. Ind. Eng. Chem. Res. 2011, 50, 7601-7607. [CrossRef]

29. Mersmann, A. Crystallization Technology Handbook; CRC Press: Boca Raton, FL, USA, 2001. 
30. Prisciandaro, M.; Olivieri, E.; Lancia, A.D. PBTC as an Antiscalant for Gypsum Precipitation: Interfacial Tension and Activation Energy Estimation. Ind. Eng. Chem. Res. 2012, 51, 12844-12851. [CrossRef]

31. Söhnel, O.; Mullin, J.W. Interpretation of crystallization induction periods. J. Coll. Int. Sci. 1988, 123, 43-50. [CrossRef]

32. Lancia, A.; Musmarra, D.; Prisciandaro, M. Measuring induction period for calcium sulfate dihydrate precipitation. AIChE J. 1999, 45, 390-397. [CrossRef]

33. Mullin, J.W. Crystallization, 4th ed.; Butterworth-Heinemann, Ltd.: Oxford, UK, 2001.

34. Söhnel, O.; Garside, J. Precipitation; Butterworth-Heinemann, Ltd.: Oxford, UK, 1992.

35. Stumm, W.; Morgan, J.J. Aquatic Chemistry: Chemical Equilibria and Rates in Natural Waters, 3rd ed.; Wiley \& Sons: New York, NY, USA, 1995.

36. Larson, T.E.; Buswell, A.M. Calcium Carbonate Saturation Index and Alkalinity Interpretations. J. Am. Water Works Ass. 1942, 34, 1667. [CrossRef]

37. Di Celso, G.M.; Prisciandaro, M.; Karatza, D.; Lancia, A.; Musmarra, D. Salt scales on process equipment: Measurement of the induction time for calcium carbonate nucleation. Can. J. Chem. Eng. 2017, 95, 1671-1675. [CrossRef]

38. Di Celso, G.M.; Prisciandaro, M.; Karatza, D.; Lancia, A.; Musmarra, D. Calcium carbonate scales on process equipment: A measure of the induction time for nucleation. Desalination Water Treat. 2017, 69, 173-177. [CrossRef]

39. Prisciandaro, M.; Di Celso, G.M.; Lancia, A.; Musmarra, D.; Karatza, D. Citric acid as a green additive to retard calcium carbonate scales on process equipment. Can. J. Chem. Eng. 2020, 98, 1973-1979. [CrossRef] 